\title{
The effect of the linoleic acid content of the diet on the fatty acid composition of the cholesterol esters isolated from the plasma of rabbits
}

\author{
By J. H. MOORE AND D. L. WILLIAMS \\ National Institute for Research in Dairying, Shinfield, Reading \\ (Received ${ }_{23}$ February 1965-Accepted I4 April 1965)
}

In an investigation into the relationships between diet, plasma lipid composition and atheromatous degeneration of the aorta in rabbits, Moore \& Williams (1964 $b$ ) observed that, irrespective of dietary treatment or absolute level of plasma cholesterol, aortic atherosis was severe when the molar ratio, phospholipid:free cholesterol in the plasma, was less than about $\mathrm{r} \cdot \mathrm{O}$. Little or no atheromatous degeneration of the aorta occurred when the ratio was greater than $1 \cdot 0$. Moore \& Williams (I964c) concluded that the protective action of high levels of dietary linoleic acid against aortic atherosis in the rabbit might be due to two separate effects on the concentration of blood lipids. In addition to exerting a pronounced hypocholesterolaemic effect, it appeared that high levels of dietary linoleic acid facilitated the maintenance of elevated levels of plasma phospholipids under conditions in which the plasma also contained high concentrations of cholesterol. In an attempt to gain further insight into the mechanism of the hypocholesterolaemic effect of dietary linoleate, a detailed study was made of the fatty acid composition of the cholesterol ester fractions isolated from the plasma samples obtained from the rabbits of Expt 2 described by Moore \& Williams $(1964 a, b)$. The results of this study are now reported.

\section{EXPERIMENTAL}

Rabbits, diets and experimental procedure. As described in detail previously (Moore $\&$ Williams, I964a), eighty-four male New Zealand White $\times$ Lop Ear rabbits, 4 months of age at the beginning of the experiment, were divided into six groups of fourteen each. The rabbits were housed in individual cages and were given food and water ad lib. To 80 parts of a semi-purified, low-fat basal diet (Moore \& Williams, I 964a) were added: for group I, 20 parts maize oil; for group 2, 20 parts butterfat; for group 3, Io parts maize oil and Io parts butterfat; for group 4, 0.47 part maize oil and $43^{\circ}$ I parts wheat starch; and for group 5, 10.2 parts maize oil and $21 \cdot 6$ parts wheat starch. The animals in group 6 were given an ordinary commercial rabbit diet. The various diets were given to the six groups of rabbits for 38 weeks, after which a sample of blood was taken from the marginal ear vein of each rabbit.

Analytical procedure. A detailed account of the methods used for the extraction of the lipids from the plasma and for the chromatographic fractionation and analysis of the plasma lipids has been given by Moore \& Doran (I962) and Moore \& Williams 
$(1964 b)$. The composition of the fatty acids present in the plasma cholesterol esters was determined by gas-liquid chromatography (Moore \& Williams, I963, 1964d).

Statistical analysis. An examination of the results for the fatty acids of the plasma cholesterol esters revealed (as with the fatty acids of the plasma phospholipids; Moore $\&$ Williams, $1964 c$ ) that the standard deviation between animals within a diet group tended to be proportional to the diet group mean. Therefore all observational values were transformed to logarithms in order to reduce heterogeneity among the withingroup variances. The tests of significance, based on the multiple-range test (Duncan, I955) as modified for unequal numbers of replications (Kramer, 1956), are summarized in Table I and refer to differences between the mean logarithmic values of each diet group. These mean logarithmic values are presented in Table $\mathrm{I}$ by their antilogarithms which are the geometric means for each diet. The arithmetic means of the untransformed values are also given in Table $\mathrm{I}$. The mean values shown in Table $\mathrm{I}$ for each group differ significantly $(P<0 \cdot 01)$ except when they share a common underlining. Thus, with the mean molar concentrations of oleic acid (I8:I) as an example, the value for group 4 is not significantly different from the values for groups 2 and 3 , yet the value for group 3 differs significantly $(P<0.01)$ from the value for group 2 . Similarly, the value for group 3 is not significantly different from the values for groups $I$ and 5 but is significantly different $(P<0.01)$ from the value for group 6 .

\section{RESULTS AND DISCUSSION}

\section{Effect of dietary treatment on the fatty acid composition of the plasma cholesterol esters}

The fatty acid compositions of the diets given to the six groups of rabbits have been reported by Moore \& Williams (I964c). The proportions of the major fatty acids present in the plasma cholesterol esters are given in Table $\mathrm{I}$ in which (and elsewhere in this paper) the shorthand designation suggested by Farquhar, Insull, Rosen, Stoffel $\&$ Ahrens (1959) is used to denote the various fatty acids. The fatty acids listed in Table I accounted for about $95 \%$ of the total fatty acids measured. The remaining $5 \%$ consisted of small amounts of $\mathrm{I}_{4}: 0, \mathrm{I}_{5}: 0, \mathrm{I}_{5}: \mathrm{I}_{1} \mathrm{I}_{5}: 0 \mathrm{br}, \mathrm{I}_{7}: 0, \mathrm{I}_{7}: \mathrm{I}$, I $7: 0$ br and $18: 3$.

The fatty acid composition of the cholesterol esters present in the plasma of the rabbits given the commercial diet (group 6) agrees remarkably well with that reported by Swell, Law, Schools \& Treadwell $(1961 b)$ for the serum cholesterol esters of rabbits given a commercial diet. The fatty acid composition of the cholesterol esters in the plasma of the rabbit would appear to be similar to that of the cholesterol esters in the plasma of man (Swell, Schools \& Treadwell, 1962a,b) but characteristically different from that of the cholesterol esters in the plasma of the rat (Swell, Law, Schools \& Treadwell, I961 $a$; Carroll, I962; Lyman, Shannon, Ostwald \& Miljanich, 1964), chick (Leveille, Tillotson \& Sauberlich, 1963) and dog (Guidry, Geer \& Robertson, 1964). Cholesterol arachidonate constitutes from 40 to $70 \%$ of the cholesterol esters of rat plasma. On the other hand, the cholesterol esters of chick plasma contain less linoleic acid and more stearic acid, whereas the cholesterol esters 
of dog plasma contain more linoleic acid and less palmitic acid than the cholesterol esters of rabbit plasma.

A comparison of the results given in Table $I$ with those for the fatty acid composition of the various diets (Moore \& Williams, 1964c) revealed that the concentration

Table I. Fatty acid composition (molar percentages) of the cholesterol esters in the plasma of the rabbits on the various dietary treatments. Ranking of means and significance of differences by the multiple-range test (Duncan, 1955; Kramer, 1956). The mean values differ significantly ( $\mathrm{P}<0.0 \mathrm{I})$ except when they share a common underlining

\begin{tabular}{|c|c|c|c|c|c|c|c|}
\hline \multirow{5}{*}{$\begin{array}{l}\text { Group no. } \\
\text { Arithmetic mean } \\
\text { Geometric mean } \\
\text { Mean log }\end{array}$} & \multicolumn{6}{|c|}{$16: 0$} & \multirow[t]{2}{*}{ units } \\
\hline & 6 & 2 & 4 & 3 & I & 5 & \\
\hline & $18 \cdot 3$ & I $8 \cdot I$ & $17 \cdot 9$ & 14.3 & I $2 \cdot 8$ & I2.5 & \multirow[b]{3}{*}{ \pm 0.068} \\
\hline & $18 \cdot I$ & 17.8 & $17 \cdot 4$ & $14 \cdot 3$ & $12 \cdot 7$ & $12 \cdot 5$ & \\
\hline & $I \cdot 26$ & I'25 & $I \cdot 24$ & I'I 5 & $I \cdot 10$ & $I \cdot 10$ & \\
\hline \multicolumn{8}{|c|}{$16: 1$} \\
\hline Group no. & 4 & 6 & 2 & 3 & 5 & $\mathbf{I}$ & \\
\hline Arithmetic mean & $6 \cdot 7$ & $4 \cdot 1$ & $3: 5$ & $2 \cdot 4$ & $2 \cdot 3$ & $I \cdot 3$ & \\
\hline Geometric mean & $6 \cdot 5$ & $4 \%$ & $3 \cdot 4$ & $2 \cdot 2$ & $2 \cdot 2$ & $\mathbf{I}-\mathbf{2}$ & \\
\hline Mean $\log$ & $0.8 \mathrm{I}$ & 0.60 & 0.53 & 0.35 & 0.34 & 0.09 & $\pm 0.04 x$ \\
\hline \multicolumn{8}{|c|}{$18: 0$} \\
\hline Group no. & 2 & 4 & 6 & 3 & 5 & $\mathbf{I}$ & \\
\hline Arithmetic mean & $5 \cdot 0$ & $3 \cdot 8$ & 3.5 & $3 \cdot 0$ & $2 \cdot 4$ & $2 \cdot 4$ & \\
\hline Geometric mean & 4.9 & 3.7 & $3 \cdot 4$ & $3 \cdot 0$ & $2 \cdot 3$ & $2 \cdot 2$ & \\
\hline Mean log & 0.69 & 0.57 & 0.54 & 0.47 & 0.37 & 0.34 & \pm 0.035 \\
\hline \multicolumn{8}{|c|}{ 18:1 } \\
\hline Group no. & 2 & 4 & 3 & $\mathbf{I}$ & 5 & 6 & \\
\hline Arithmetic mean & $50 \cdot 6$ & $45 \cdot 8$ & $39^{\cdot} 6$ & 34.0 & $32 \cdot 6$ & $27 \cdot 9$ & \\
\hline Geometric mean & 50.1 & $44 \cdot 5$ & $38 \cdot 6$ & $33 \cdot 9$ & $32 \cdot 3$ & $27 \cdot 2$ & \\
\hline Mean log & 1.70 & $x \cdot 65$ & $\mathrm{I} \cdot 59$ & $1 \cdot 53$ & $I \cdot 5 \mathrm{I}$ & $I \cdot 44$ & \pm 0.025 \\
\hline \multicolumn{8}{|c|}{$18: 2$} \\
\hline Group no. & $\mathbf{1}$ & 5 & 6 & 3 & 4 & 2 & \\
\hline Arithmetic mean & $46 \cdot 5$ & $46 \cdot 3$ & $36 \cdot 6$ & $35 \cdot 7$ & $20 \cdot 0$ & I6. I & \\
\hline Geometric mean & $46 \cdot 3$ & $46 \cdot 1$ & $35 \cdot 8$ & $3 I \cdot 6$ & $18 \cdot 9$ & I $4: 3$ & \\
\hline Mean log & $1 \cdot 67$ & $r \cdot 66$ & $\mathrm{I} \cdot 55$ & $1 \cdot 50$ & $I \cdot 28$ & $I \cdot I 6$ & \pm 0.046 \\
\hline \multicolumn{8}{|c|}{$20: 4$} \\
\hline Group no. & 6 & 5 & 2 & 4 & 3 & $\mathbf{I}$ & \\
\hline Arithmetic mean & $1 \cdot 8$ & $I \cdot I$ & 0.9 & 0.9 & 0.8 & 0.7 & \\
\hline Geometric mean & $1 \cdot 6$ & $I \cdot I$ & 0.9 & 0.8 & 0.8 & $0 \cdot 6$ & \\
\hline Mean log & 0.22 & 0.02 & -0.04 & -0.08 & -0.12 & -0.22 & \pm 0.053 \\
\hline
\end{tabular}

Average
standard error
of the mean
(66 df), log
units

\pm 0.068

Group r, 20\% maize-oil diet; group 2, 20\% butterfat diet; group 3, ro\% maize-oil, 10\% burterfat diet; group 4, low-fat, high-starch diet; group 5, 10\% maize-oil, starch diet; group 6, commercial diet.

Certain of the animals died during the experiment. The numbers of animals at the end of the experiment were: group I, 12; group 2, 13; group 3, 13; group 4, 12; group 5, 10; group 6, 12.

of palmitoleic acid in the plasma cholesterol esters was not determined simply by the palmitoleic acid content of the diet. Indeed, there would appear to be an inverse curvilinear relationship between the concentration of palmitoleic acid in the plasma 
cholesterol esters and the total unsaturated fatty acid (i.e. I6:I + I8: I $+18: 2$ ) content of the diet (Fig. I). It is possible that the endogenous synthesis of palmitoleic acid was inhibited to some extent by high levels of unsaturated fatty acids in the diet. It has been reported that the concentration of palmitoleic acid in the plasma cholesterol esters of man also decreases when the diet is supplemented with unsaturated fatty acids (Okey, Lee, Hampton \& Miljanich, 1960; Swell et al. 1962a,b). The concentrations of palmitic, stearic and oleic acids in the plasma cholesterol esters were not

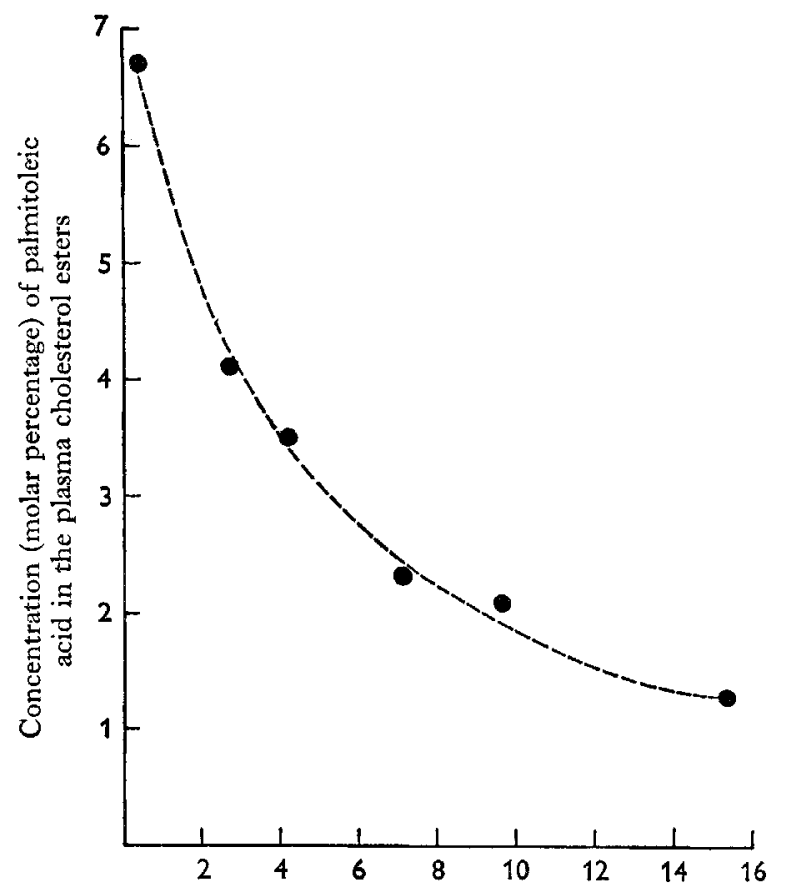

Total unsaturated fatty acid content $(\mathrm{g} / \mathrm{1} / 00 \mathrm{~g})$ of diet

Fig. I. Relationship between the concentration of palmitoleic acid in the plasma cholesterol esters of the rabbits and the total unsaturated fatty acid content of the experimental diets. Mean values for each group; for numbers of animals see Table 1.

directly related to the levels of these acids in the various diets. On the other hand, the level of linoleic acid in the diet did exert some influence on the concentration of linoleic acid in the plasma cholesterol esters. Low concentrations of linoleic acid were observed in the cholesterol esters of the plasma in the rabbits of group 2 (given the high-butterfat diet containing $0.27 \%$ linoleic acid) and group 4 (given the highstarch diet containing $0.21 \%$ linoleic acid). When half of the supplementary butterfat given to the rabbits of group 2 and half of the supplementary starch given to the rabbits of group 4 were isocalorically replaced by maize oil (in the diets given to the rabbits of groups 3 and 5 , respectively) there was a significant increase in the concentration of linoleic acid in the plasma cholesterol esters. However, the concentration of linoleic acid in the plasma cholesterol esters of the rabbits in group I (given the diet containing $10.6 \%$ linoleic acid) was not significantly higher than that in the plasma 
cholesterol esters of the rabbits in groups 3 and 5 (given diets containing 5.4 and $4.9 \%$ linoleic acid respectively). Thus, as with the plasma phospholipids (Moore \& Williams, 1964c), there would appear to be a limit to the extent to which the concentration of linoleic acid in the plasma cholesterol esters of the rabbit may be elevated by increasing the linoleic acid content of the diet.

Although linoleic acid is a precursor in the synthesis of arachidonic acid in animal tissues (Mead, Steinberg \& Howton, 1953; Mead, Slaton \& Decker, 1956; Mead \& Howton, 1957), it should be noted that the concentration of arachidonic acid in the plasma cholesterol esters remained very low even when the rabbits were given the diet containing $20 \%$ maize oil (group I). This particular aspect of lipid metabolism in the rabbit would therefore appear to be similar to that in man. Irwin \& Wiese (r96r), Swell et al. (1962a, b) and Holman, Caster \& Wiese (1964) have shown that the concentration of arachidonic acid in the cholesterol esters of human plasma does not increase when the linoleic acid content of the diet is increased. Moore \& Williams $(1963)$ have also found that the concentration of arachidonic acid in the cholesterol esters, phospholipids and triglycerides of the liver was not increased when rabbits were given a diet containing $20 \%$ maize oil. It is possible therefore that the enzyme system that is involved in the conversion of linoleic acid into arachidonic acid is not particularly active in the liver of the rabbit. On the other hand, the enzymes concerned with the incorporation of fatty acids into the cholesterol esters, phospholipids and triglycerides of rabbit liver may have low specificity towards arachidonic acid. Alternatively, there might be a preferential oxidation of arachidonic acid in the tissues of the rabbit. Swell et al. (196I $b$ ) have shown that the arachidonic acid content of the liver and serum lipids of the rabbit was not increased even when arachidonic acid was added to the diet. In this respect again, the lipid metabolism of the rabbit differs markedly from that of the rat. The concentration of tetraenoic acid in the plasma cholesterol esters of the rat is considerably increased when the linoleic acid content of the diet is increased (Klein, 1957). According to Mohrhauer \& Holman (1963) the arachidonic acid content of the liver lipids of the rat increases when the diet is supplemented either with linoleic acid or with arachidonic acid.

\section{Relationships between the fatty acid compositions of the plasma and liver cholesterol esters and observations on the origin of the plasma cholesterol esters}

There is considerable evidence (Haft, Roheim, White \& Eder, r 962; Havel, Felts \& Van Duyne, 1962; Roheim, Haft, Gidez, White \& Eder, 1963; Marsh, 1963) that the liver is the major source of both the lipid and protein moieties of the circulating plasma lipoproteins. It might be expected therefore that the fatty acid composition of the various lipid fractions in the plasma would be similar to that of the corresponding lipid fractions in the liver. However, the proportions of the various cholesterol esters present in the plasma of the rabbit appear to be characteristically different from those of the cholesterol esters present in the liver of the rabbit. In this study the breed, strain and source of the rabbits, the experimental procedure and three of the experimental diets (i.e. the $20 \%$ maize-oil diet, the $20 \%$ butterfat diet and the low-fat, high-starch diet) were identical with those of a previous study (Moore \& Williams, 
1963) on the effect of diet on the composition of the liver cholesterol esters. It would seem justified, therefore, to compare the results obtained in both studies for the fatty acid composition of the plasma and liver cholesterol esters. This comparison is shown in Table 2. Irrespective of dietary treatment, the concentrations of palmitic and palmitoleic acids in the plasma cholesterol esters were about the same as the corresponding concentrations of the acids in the liver cholesterol esters. On the other hand, the plasma cholesterol esters contained a much higher proportion of cholesterol linoleate but considerably lower proportions of cholesterol stearate and cholesterol oleate than did the liver cholesterol esters. These differences in fatty acid composition of the plasma and liver cholesterol esters are very similar to those observed by Swell et al. $(\mathrm{I} 96 \mathrm{I} b)$ and Swell, Law \& Treadwell (1962) for the serum and liver cholesterol

Table 2. Comparison of the fatty acid compositions (molar percentages) of the cholesterol esters in the liver and plasma of experimental rabbits on three dietary treatments

\begin{tabular}{|c|c|c|c|c|c|c|}
\hline \multirow[b]{2}{*}{ Fatty acid } & \multicolumn{2}{|c|}{$20 \%$ maize-oil diet } & \multicolumn{2}{|c|}{$20 \%$ butterfat diet } & \multicolumn{2}{|c|}{ Low-fat, high-starch diet } \\
\hline & Liver & Plasma & Liver & Plasma & Liver & Plasma \\
\hline $16: 1$ & $I \cdot 3$ & $\mathbf{I} \cdot 3$ & $3 \cdot 9$ & $3 \cdot 5$ & $8 \cdot 0$ & $6 \cdot 7$ \\
\hline $16: 0$ & $12 \cdot 1$ & 12.8 & $19 \cdot 4$ & $18 \cdot 1$ & 16.9 & $\mathbf{1} 79$ \\
\hline $18: 0$ & 8.0 & $2 \cdot 4$ & $6 \cdot 4$ & $5 \cdot 0$ & $5 \cdot 6$ & $3 \cdot 8$ \\
\hline I8: I & $38 \cdot 6$ & $34 \cdot 0$ & $56 \cdot 6$ & $50 \cdot 6$ & $50 \cdot 3$ & $45 \cdot 8$ \\
\hline $18: 2$ & 30.4 & $45^{\cdot 6}$ & $7 \cdot 9$ & $16 \cdot I$ & $11 \cdot 5$ & 200 \\
\hline $20: 4$ & $2 \cdot 0$ & 0.7 & 0.6 & 0.9 & $I \cdot 7$ & 0.9 \\
\hline
\end{tabular}

Values for the liver cholesterol esters from Moore \& Williams (1963).

esters of rabbits given various experimental diets. An analogous partition of the polyunsaturated fatty acids between the plasma and liver cholesterol esters would appear to occur in other species. For instance, in rats (Swell et al. 1961 $a$ ), chicks (Leveille et al. 1963) and man (Swell, Field, Schools \& Treadwell, r960) the plasma cholesterol esters contain higher proportions of the polyunsaturated acids than do the liver cholesterol esters. These differences in fatty acid composition between liver and plasma cholesterol esters could possibly be due to the preferential utilization of certain of the liver cholesterol esters (i.e. the polyunsaturated acid esters) for the synthesis of plasma lipoproteins (Roheim et al. 1963; Goodman \& Shiratori, 1964). In this respect it should be noted that Klein \& Martin (1959) have reported heterogeneous turnover rates for the various cholesterol esters present in rat liver. Nevertheless, it is also possible that the higher concentrations of polyunsaturated acids in the plasma cholesterol esters might be the result of a transesterification reaction occurring in the plasma whereby a proportion of the plasma free cholesterol is esterified with the polyunsaturated fatty acids derived from the $\beta$-position of the plasma lecithin (Glomset, I962, I963; Glomset, Parker, Tjaden \& Williams, 1962). The compositions of the fatty acids occupying the $\beta$-position of the lecithin isolated from pooled samples of the plasma lipids obtained from each of the six groups of rabbits used in our study have been determined by Moore, Williams \& Westgarth (1965). Comparison of the results given in Table $\mathrm{I}$ with those found by Moore et al. (1965) revealed that in the rabbits of the experiment described here there was a highly significant 
positive rectilinear relationship between the mean values for the concentration of linoleic acid in the plasma cholesterol esters and those for the concentrations of linoleic acid in the $\beta$-position of the plasma lecithin samples (Fig. 2). This relationship would certainly be consistent with, but of course does not necessarily prove, the existence in rabbit plasma of a transesterification mechanism involving the free cholesterol and the linoleic acid present in the $\beta$-position of the lecithin.

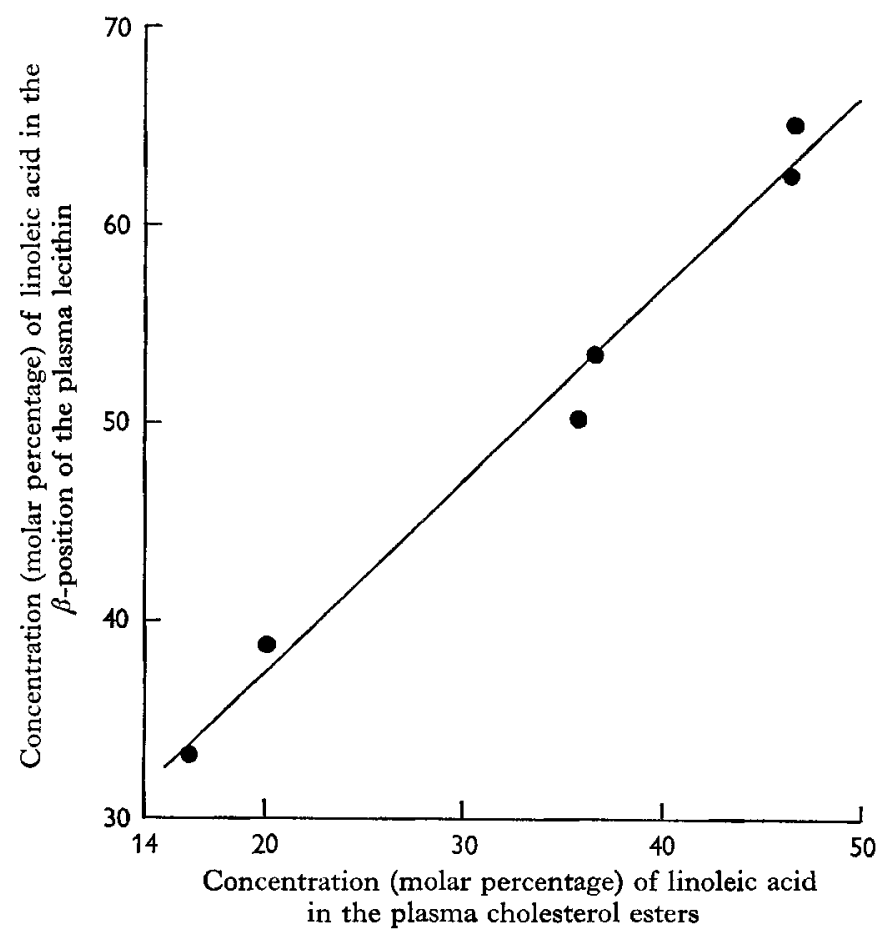

Fig. 2. Relationship between the concentration of linoleic acid in the $\beta$-position of the plasma lecithin $(y)$ and the concentration of linoleic acid in the plasma cholesterol esters $(x)$ of the experimental rabbits. Mean values for each group; for numbers of animals see Table $I$. Regression equation, $y=17.85+0.973 x$; standard error of slope, \pm 0.061 ; correlation coefficient, 0.993 (significant at $0.01>P>0.001$ ).

\section{Relationship between the fatty acid composition of the plasma cholesterol esters and the concentration of cholesterol in the plasma}

The effects of the different dietary treatments on the concentrations of the various lipid fractions (i.e. free cholesterol, cholesterol ester, triglyceride, free fatty acids and phospholipids) in the plasma of the rabbits of this investigation have been reported previously (Moore \& Williams, I964b). It is of interest now to consider whether the level of cholesterol in the plasma was related in any way to the fatty acid composition of the plasma cholesterol esters. A detailed examination of the results obtained for the individual rabbits on all six dietary treatments revealed that there were highly significant inverse rectilinear relationships between the concentration of linoleic acid in the plasma cholesterol esters on the one hand and the concentrations of total 
cholesterol and cholesterol ester in the plasma on the other (Table 3 ). Relationships similar to those given in Table 3 have been shown to exist in the plasma of man (Lewis, 1958; Wright, Pitt \& Morton, I959; Swell et al. 1962a, b). A particularly interesting observation is that of Lewis $\left(195^{8}\right)$ who noted that when hydrogenated coconut oil in the diet of human subjects was replaced by sunflower-seed oil the increase in the concentration of linoleic acid in the plasma cholesterol esters occurred before there was a significant fall in the concentration of cholesterol in the plasma.

Table 3. Relationships between the concentration of linoleic acid in the plasma cholesterol esters and the concentrations of total cholesterol and cholesterol esters (calculated as cholesterol oleate) in the plasma of the experimental rabbits

\begin{tabular}{|c|c|c|c|c|}
\hline \multicolumn{2}{|c|}{ Comparison } & \multirow[b]{2}{*}{ Regression equation } & \multirow{2}{*}{$\begin{array}{l}\text { Standard } \\
\text { error of } \\
\text { slope }\end{array}$} & \multirow{2}{*}{$\begin{array}{c}\text { Correlation } \\
\text { coefficient }\end{array}$} \\
\hline$y$ & $x$ & & & \\
\hline $\begin{array}{l}\text { Concentration }(\mathrm{mg} / \mathrm{I} 00 \mathrm{ml}) \\
\text { of total cholesterol in } \\
\text { plasma }\end{array}$ & $\begin{array}{l}\text { Concentration (molar } \\
\text { percentage) of linoleic } \\
\text { acid in plasma } \\
\text { cholesterol esters }\end{array}$ & $y=133 \cdot 9-1 \cdot 65 x * * *$ & \pm 0.279 & $-0.577^{* * *}$ \\
\hline $\begin{array}{l}\text { Concentration }(\mathrm{mg} / \mathrm{ro0} \mathrm{ml}) \\
\text { of cholesterol ester in } \\
\text { plasma }\end{array}$ & $\begin{array}{l}\text { Concentration (molar } \\
\text { percentage) of linoleic } \\
\text { acid in plasma } \\
\text { cholesterol esters }\end{array}$ & $y=60.16-0.572 x * * *$ & \pm 0.143 & $-0.539^{* * *}$ \\
\hline
\end{tabular}

$$
\text { *** } P<0.001
$$

The concept that polyunsaturated fatty acids play an important part in the transport of cholesterol in the body probably arose from the work of Alfin-Slater, Aftergood, Wells \& Deuel (1954) who showed that cholesterol esterified predominantly with saturated and monounsaturated fatty acids accumulated in the livers of rats deficient in essential fatty acids, and from that of Peifer \& Holman (1955) who found that the requirement of the rat for essential fatty acids was increased when cholesterol was added to the diet. The process of elimination of cholesterol from the body involves the secretion in the bile of cholesterol and bile acids. Although bile acids are derived from cholesterol by a metabolic pathway that still awaits complete elucidation, there is some evidence from isotope experiments that bile acids and bile cholesterol are derived from the plasma cholesterol ester rather than the plasma free cholesterol (Hellman \& Rosenfeld, I959). The important question that now arises is whether the cholesterol esterified with polyunsaturated acids is utilized more efficiently for the production of bile acids and bile cholesterol than is the cholesterol esterified with saturated and monounsaturated fatty acids. This question cannot be answered at present, but the work of Boyd (1962) certainly seems to indicate that dietary linoleic acid accelerates the katabolism of the plasma cholesterol in the rat. As Boyd (1962) has tentatively suggested, it is possible that hydroxylation in the 7-position of the steroid nucleus of cholesterol (a step in the cholesterol-bile acid transformation) might be facilitated if the cholesterol is esterified with linoleic acid.

In conclusion, therefore, the relationship shown in Table 3 , although as yet difficult 
to explain in terms of a biochemical mechanism, would seem to indicate that the hypocholesterolaemic effect of dietary linoleic acid is proportional to the extent to which the linoleic acid is incorporated into the plasma cholesterol esters.

\section{SUMMARY}

I. Groups of male rabbits (ten to thirteen per group survived) were given ad lib. a diet consisting of 80 parts of a low-fat basal diet to which were added: for group I, 20 parts maize oil; for group 2, 20 parts butterfat; for group 3, 10 parts maize oil and ro parts butterfat; for group 4, 0.47 part maize oil and 43.1 parts wheat starch; and for group $5,10 \cdot 2$ parts maize oil and 21.6 parts wheat starch. The animals in group 6 were given an ordinary commercial rabbit diet.

2. The rabbits were given the various diets for a period of 38 weeks, after which a large sample of blood was taken from each animal. The plasma lipids were fractionated on columns of silicic acid and the fatty acid composition of the plasma cholesterol esters was determined by gas-liquid chromatography.

3. Palmitic, palmitoleic, stearic, oleic, linoleic and arachidonic acids accounted for about $95 \%$ of the total fatty acids of the plasma cholesterol esters.

4. There appeared to be an inverse curvilinear relationship between the concentration of palmitoleic acid in the plasma cholesterol esters and the total unsaturated fatty acid content of the diet. There seemed to be a limit to the extent to which the concentration of linoleic acid in the plasma cholesterol esters could be increased by supplementing the diet with linoleic acid. On all dietary treatments the concentration of arachidonic acid in the plasma cholesterol esters was low and was not influenced apparently by the linoleic acid content of the diet.

5. Comparison of the fatty acid composition of the plasma cholesterol esters with that of the liver cholesterol esters for rabbits given the $20 \%$ maize-oil diet, the $20 \%$ butterfat diet or the low-fat, high-starch diet revealed considerably higher concentrations of linoleic acid but consistently lower concentrations of stearic and oleic acids in the plasma cholesterol esters. There was a significant positive rectilinear relationship between the concentration of linoleic acid in the plasma cholesterol esters and the concentration of linoleic acid in the $\beta$-position of the plasma lecithin.

6. There were highly significant inverse rectilinear relationships between the concentration of linoleic acid in the plasma cholesterol esters and the concentration of total cholesterol and cholesterol ester in the plasma.

7. The hypocholesterolaemic effect of dietary linoleic acid appeared to be proportional to the extent to which linoleic acid was incorporated into the plasma cholesterol esters.

The authors are grateful to Professor S. K. Kon for his encouragement and advice, to Mr D. R. Westgarth for guidance on the statistical analysis of the results, and to Miss J. Carrinci and Miss A. Broadbent for their skilful assistance. This study was supported by a grant from the Butter Information Council. 


\section{REFERENCES}

Alfin-Slater, R. B., Aftergood, L., Wells, A. F. \& Deuel, H. J. Jr. (1954). Arch. Biochem. Biophys. 52, I80.

Boyd, G. S. (1962). Fed. Proc. 2r, Suppl. I I, p. 86.

Carroll, K. K. (1962). Canad. F. Biochem. Physiol. 40, 1115.

Duncan, D. B. (I955). Biometrics, II, I.

Farquhar, J. W., Insull, W., Rosen, P., Stoffel, W. \& Ahrens, E. H. Jr. (I959). Nutr. Rev. r7, Suppl.

Glomset, J. A. (1962). Biochim. biophys. Acta, 65, 128.

Glomset, J. A. (1963). Biochim. biophys. Acta, 70, 389 .

Glomset, J. A., Parker, F., Tjaden, M. \& Williams, R. H. (1962). Biochim. biophys. Acta, 58, 398.

Goodman, D. S. \& Shiratori, T. (I964). F. Lipid Res. 5, 578.

Guidry, M. A., Geer, J. C. \& Robertson, W. B. (1964). Circulation Res. 14, 61.

Haft, D. E., Roheim, P. S., White, A. \& Eder, H. A. (Ig62). F. clin. Invest. 4I, 842.

Havel, R. J., Felts, J. M. \& Van Duyne, C. M. (1962). F. Lipid Res. 3, 297.

Hellman, L. \& Rosenfeld, R. S. (I959). In Hormones and Atherosclerosis, p. 157. [G. Pincus, editor.] New York: Academic Press Inc.

Holman, R. T., Caster, W. O. \& Wiese, H. F. (1964). Amer. J. clin. Nuir. 14, 193.

Irwin, M. I. \& Wiese, H. F. (196r). f. Nutr. 74, 217.

Klein, P. D. (1957). Arch. Biochem. Biophys. 72, 238.

Klein, P. D. \& Martin, R. A. (1959). F. biol. Chem. 234, I685.

Kramer, Y. K. (1956). Biometrics, r2, 307.

Leveille, G. A., Tillotson, J. A. \& Sauberlich, H. E. (1963). F. Nutr. 81, 357.

Lewis, B. (1958). Lancet, ii, 7 I.

Lyman, R. L., Shannon, A., Ostwald, R. \& Miljanich, P. (1964). Canad. Y. Biochem. 42, 365.

Marsh, J. B. (1963). F. biol. Chem. 238, 1752 .

Mead, J. F. \& Howton, D. R. (1957). F. biol. Chem. 239, 575.

Mead, J. F., Slaton, W. H. Jr. \& Decker, A. B. (1956). F. biol. Chem. 218, 401.

Mead, J. F., Steinberg, G. \& Howton, D. R. (I953). F. biol. Chem. 205, 683.

Mohrhauer, H. \& Holman, R. T. (1963). F. Lipid Res. 4, 15 I.

Moore, J. H. \& Doran, B. M. (1962). Biochem. F. 84, 506.

Moore, J. H. \& Williams, D. L. (r963). Canad.F. Biochem. Physiol. 41, 182 I.

Moore, J. H. \& Williams, D. L. (1964a). Brit. F. Nutr. 18, 253.

Moore, J. H. \& Williams, D. L. (1964b). Brit. F. Nutr. 18, 431 .

Moore, J. H. \& Williams, D. L. (1964c). Brit. F. Nutr. 18, 603.

Moore, J. H. \& Williams, D. L. (r964d). Biochim. biophys. Acta, 84, 4I.

Moore, J. H., Williams, D. L. \& Westgarth, D. R. (1965). Biochim. biophys. Acta. (In the Press.)

Okey, R., Lee, M., Hampton, M. C. \& Miljanich, P. (ז960). Metabolism, 9, 79 r.

Peifer, J. J. \& Holman, R. T. (1955). Arch. Biochem. Biophys. 57, 520.

Roheim, P. S., Haft, D. E., Gidez, L. I., White, A. \& Eder, H. A. (1963). F. clin. Invest. $42,1277$.

Swell, L., Field, H., Schools, P. E. Jr. \& Treadwell, C. R. (1960). Proc. Soc. exp. Biol., N. Y., ro3, $65 \mathrm{I}$.

Swell, L., Law, M. D., Schools, P. E. Jr. \& Treadwell, C. R. (1961 a). F. Nutr. 74, 148.

Swell, L., Law, M. D., Schools, P. E. Jr. \& Treadwell, C. R. (1961 b). F. Nutr. 75, I81.

Swell, L., Law, M. D. \& Treadwell, C. R. (1962). F. Nutr. 76, 429.

Swell, L., Schools, P. E. Jr. \& Treadwell, C. R. (1962a). Proc. Soc. exp. Biol., N. Y., rog, 682.

Swell, L., Schools, P. E. Jr. \& Treadwell, C. R. (1962b). Proc. Soc. exp. Biol., N.Y., III, 48.

Wright, A. S., Pitt, G. A. J. \& Morton, R. A. (1959). Lancet, ii, 594. 